a preserved milk special legislation does seem absolutely necessary. And such legislation to satisfy the requirements of the public health should provide that no preservative. whatever the use of which is not sanctioned by the Local Government Board or the Board of Agriculture should be used for milk; that the proportion of such preservative should not exceed a certain maximum amount to be fixed officially; that the nature of the milk should be declared by the vendor, and that it should be sold only as " preserved milk." And, finally, the penalties for infringement of the law should be sufficiently heavy to render the sale of "preserved milk" as fresh milk unprofitable.

With regard to other articles of food special cases must be dealt with on their own merits, but I do not think that there is any other article of food in which the use of a preservative is so important as it is in the case of milk. It is, for instance, difficult to find any good reason for the presence of salicylic acid or other special preservative in such articles of food as jam, cheese, and pickles, whilst the use of certain preservatives as substitutes for alcohol is a matter of fraud pure and simple. So also the use of a tasteless preservative in butter cannot be regarded as other than fraudulent unless the fact is declared; by using such a preservative the vendor is enabled to sell as fresh butter what under former conditions would have been sold at a lower price as salt butter. The use of boric acid, again, for salting bacon and ham may or may not cause injury to the consumer, but in any case the latter should have the opportunity of exercising his own judgment on the matter as to whether he will eat that class of preserved food. And, in short, it appears to me that if the regulations suggested above for milk were applied to all other articles of food of a perishable nature the requirements of the public health would be safe-guarded as far as possible, and at the same time the legitimate use of preservatives would not be interfered with.

Sutton, Surrey.

\section{THREE CASES OF PELVIC TROUBLE CAUSED BY BICYCLING.}

BY SKENE KEITH, M.B., F.R.C.S. EDIN.

AN experience of only three cases where bicycling has necessitated treatment of the pelvic organs is so small that if others have met with similar cases in anything approaching the same proportion it may be safely affirmed that the amusement is a safe one for all fairly healthy women in so far as that region of the body is concerned. The physician, doubtless, will meet with a greater number of bad results when he examines the chest. It is reasonable to expect that when a woman, or for the matter of that a man, of 30 years, 40 years, or 50 years of age takes up for the first time in life any form of athletics and competes with those who have been accustomed to such exercises, that in a certain number the heart will not be able to bear the strain. The question naturally arises, What is moderation in bicycling? This depends on many things ; in the case of a woman on the person herself, on the roads, whether they are billy or level, smooth, rough, or heavy, on the machine, and on various other conditions. No average distance, therefore, can be fixed. 10 miles may be too much for some and 40 miles not too much for others. Two of the three cases presented special points of interest. The predominant symptom in both was melancholia, apparently due to some derangement in the pelvic circulation. In the one case there was a retroversion of the uterus and in the other the most prominent sign was an anteversion of the aterus.

CASE 1.-The injury in this case was due to an accident and might have occurred had the patient been driving in any other way, so that it is hardly fair to credit bicycling with the result. In the summer-time the patient, a woman, aged 22 years and unmarried, was rapidly descending a hill when a dog ran in front of the machine and she fell, being much shaken, but as far as she knew she received no special injury. For the next two weeks, until the menstrual period came on, she felt fair'y well but a little dull. The flow of the menses was not natural, the quantity being much less than usual, but there was no pain. The next month there was no flow and the patient felt depressed and chilly. Her medical man was consulted and prescribed some medicine which brought on a slight bæmorrhagic discharge from the womb, but as the depression increased he took her to one of the best-known gynæcologists in the north. This was three months after the accident. An internal examination was made and the uterus was found to be very slightly retroverted. A month afterwards I saw her, when she had the typical appearance of a patient suffering from melancholia. She complained of a great feeling of cold but of no pain. The hands and feet were of icy coldness-even sitting close "into the fire" she said she felt cold-and there was no perspiration. Her friends told me that she would sit all day with a book and this often upside down. On examination I found a complete retroversion, so that in a month the uterus had gradually turned over. Of this there can be no doubt. As confirmatory of the truth of this the melancholia had steadily increased and the feeling of cold was more intensified. The uterus could be replaced with the sound, but only by using a certain amount of force. When it was held in position by the instrument a decided amount of general swelling could be felt in the posterior fornix. The ovaries were not made out. As soon as the sound was removed the uterus retroverted slightly. Several pessaries were tried which failed to keep the uterus in position or to relieve the symptoms, and as the difficulty seemed to lie in the thickening behind the nterus hot-water injections were ordered. While these were being given an almost normal period came on, without, however, lessening the melancholia. At the end of nearly three weeks an examination was again made. The uterus was found to be looser and could be turned up more easily, but as there was still some backward dragging a ring pessary only was introduced. This kept the uterus well up; though with a very slight backward displacement. The organ was now probably in a better position than it had been when the first examination was made. Recovery was almost instantaneous. By night the patient felt warm, she perspired freely while in bed, and by the next morning she was perfectly well. With the exception of one severe attack of pelvic pain the patient has had no return of her trouble. She is now married and has been delivered of her first child.

I do not think that one could have a more perfect example of the well-known fact that it is not the displacement which is of importance, but that it is the result of the displacement which must be cured-the natural effort at cure being directed to the original cause. When first examined there was a slight retroversion and when she was cured there was still a slight retroversion, but in the meantime the result of the misplacement had been removed. The hot water alone did not make the patient well, but it put her in the position to be made well by the pessary.

CASE 2.-I first saw this case in October, 1894. The patient was 33 years of age; she had been married five years and she had had two children, the younger being 16 months old. She had had a great deal of worry and the birth of the second child brought her troubles to a head. For a time she was quite melancholic. A number of medical men had been consulted and the Weir-Mitchell treatment had been tried but had to be discontinued after a very short time. Eventually she went abroad. When I saw her she was nearly well and my note of the state of the pelvis is, "Uterus heavy and lying forwards, with slight cervical tear, but giving rise to no trouble." I did not hear of her again till October, 1897. In the interval she had been quite well until the May preceding, when she felt something "seem to go wrong" in her inside while she was learning to bicycle. She consulted her medical adviser who put in a Hodge pessary. Gradually but steadily the old feeling of depression came on and by August she began to wish to leave her home, her husband, and her children, and go away somewhere by herself. As her own medical man was absent she consulted a stranger, who said that the depression was due to gout and that she must go to Homburg to be cured. When she arrived there the practitioner whom she consulted said that she was not a suitable case, but gave her some treatment. After being in the country for two months and gradually getting worse she came to see me at the very end of October. Such was the history of the case except that she had been for some time losing more at the periods, which appeared every three weeks. The state of the uterus had changed-it was about half again as large as it had been, it was very much barder, and i wa- more antererted. She was still wearing the pessary which had been inserted in May. ? he depression 
was always great, but it was at its depth during the periods, and she had frequent attacks of sleeplessness. To my mind the mental condition was caused by the hardness and anteversion of the uterus. The history indicated that something was felt internally in May, that this was followed by the gradually increasing melancholia, and that a distinct change had occurred in the local condition. Taking up this position, the only natural form of treatment seemed to me to be one which would soften the uterus and reduce its bulk. This I advised should be done by electricity and this treatment was carried out. Marked improvement did not come quickly, but when it did it coincided with the softening and gradual elevation of the uterus. 25 applications in all were made, and it was only when the treatment was nearly finished that the patient began to have any desire to go home. Before she left the menstrual interval had gone back to four weeks instead of three weeks. Within two or three months of going home she was completely restored to health and spirits and some months later she became pregnant. I did not remove the original Hodge pessary, which raised the pelvic contents well, as the uterus became lighter.

CASE 3.-This case need not be referred to at length as it presents no special features of interest. There was a retroversion with a prolapsed ovary and the symptoms began very definitely at the time when the patient was learning to bicycle.

Charles-street, Berkeley-square, W.

\section{CASE OF TRAUMATIC ANEURYSM OF THE CAROTID ARTERY CAUSED BY A SEWING-NEEDLE.}

BY EDWARD H. DOUTY, M.A., M.D. CANTAB., \&c., LATE ASSISTANT SURGEON TO ADDENBROOKE'S HOSPITAL, CAMBRIDGE

So far as I know, the following case is a unique instance of its kind, and it would therefore appear desirable that it should be placed on record. I am indebted to Mr. J. B. Byles, senior house surgeon to Addenbrooke's Hospital, for the notes on the condition of the patient on admission to hospital, together with the history of the case up to the operation.

The patient, a man, 62 years of age, was thin but healthy in appearance. There was no history of syphilis or of other previous illness of any importance. His occupation was that of a millwright. The symptoms of his present trouble commenced on August 10th, 1898. On that day he complained of sore-throat, with difficulty of, and pain on, swallowing, and his medical attendant treated him with gargles, \&c., and kept him in bed. On the 29th he noticed a lump on the right side of his neck and on the following day he began to spit blood. This latter symptom continued until his admission to the hospital on the 31st. The blood was bright-red in colour and frothy in character. It was generally expectorated in small quantities, but it was stated that twice before admission the patient was " nearly choked" by a sudden rush of a pint or more than a pint of blood.

On examination a pulsating swelling was found on the right side of the neck reaching from the angle of the jaw down to the clavicle. A thrill and a loud bruit synchronous with the systole of the heart were present over the swelling. The area of cardiac dulness was normal. On auscultation nothing abnormal could be detected in the heart sounds, save that the aortic second sound was accentuated. There was no appreciable difference between the radial pulses on the two sides, but the right temporal pulse was markedly smaller than the left and also delayed in time. The right pupil was contracted. Digital examination of the pharynx revealed an ulcer behind and below the epiglottis on the right side. It was from this point that the blood appeared to come.

On August 31st, a few hours after admission, I operated on the patient. The swelling extended so far down that I thought it necessary to tie the innominate artery. I explored the innominate, but finding that the proximal part of the carotid artery was healthy I tied this latter artery with two silk ligatures about a quarter of an inch from the bifurcation. The pulsation of the tumour ceased absolutely. There was much restlessness after the operation, but this was controlled by hypodermic injections of one-sixth of a grain of morphia. On two occasions during the following day there was marked left unilateral sweating of the face and head; each time this symptom lasted for about an hour. A small quantity of blood was expectorated in the afternoon. In the evening the patient was again very restless and the pulse became weak. He died suddenly at 10 P.M. For the following careful notes of the post-mortem examination I am indebted to the late Professor Kanthack.

On opening up the incision the artery was found to be securely tied by double ligatures. There was no aneurysmal dilatation below the ligatures. The first part of the aortic arch appeared to be dilated, but when opened up afterwards there was nothing abnormal to be seen and its circumference was normal in extent. Tracing the common carotid up it lost itself in a mass which was copiously suffused with blood, so that it was impossible to dissect ont the various structures. The carotid artery, however, did not open into anything like an aneurysmal sac. While dissecting the parts out the mass broke down and much soft coagulum appeared. The

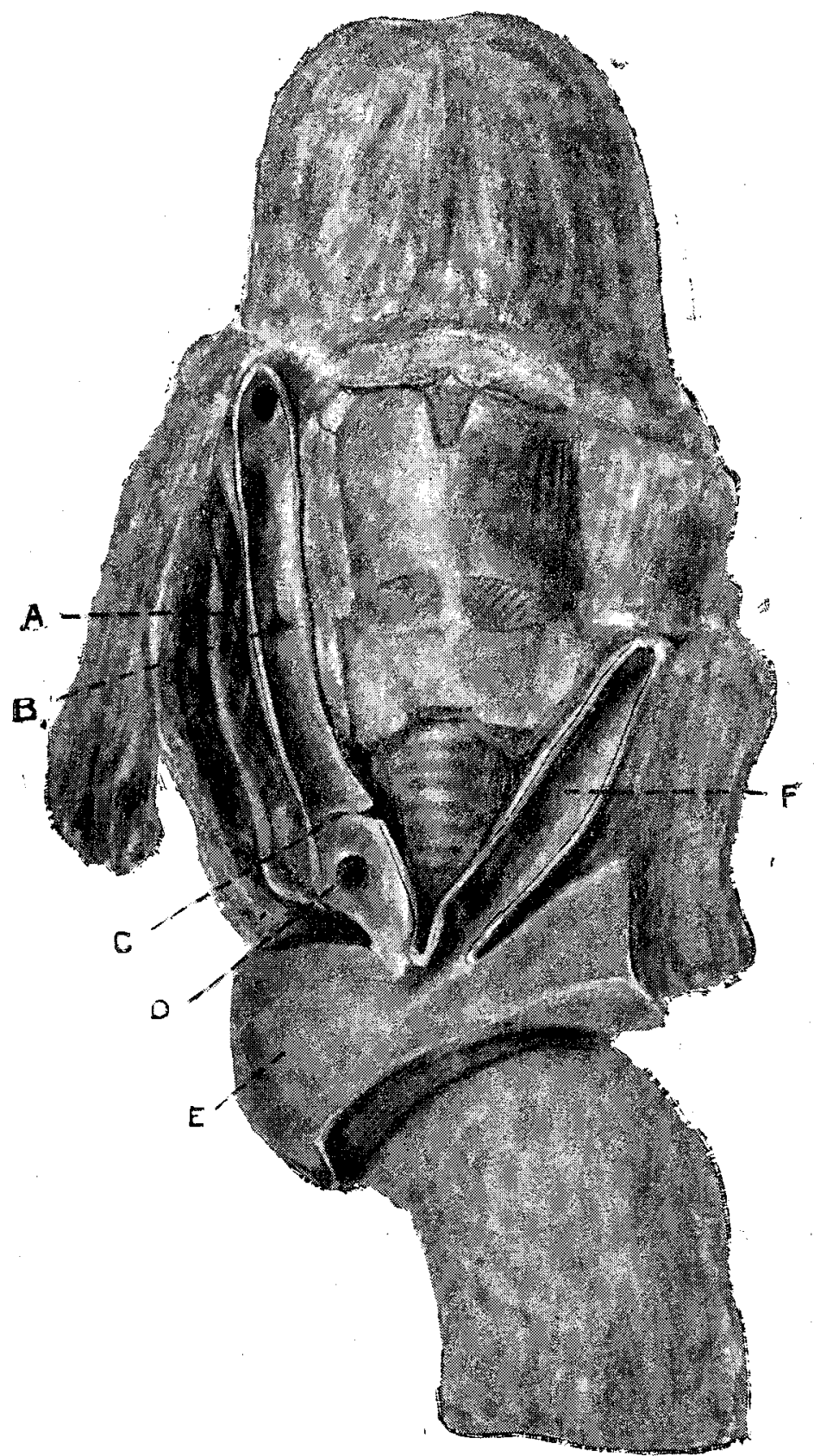

A, Needle. B, Opening in the right carotid artery. c, The point of ligature. D, Orifice of tne right subclavian artery. E, Aorta. F, The left carotid artery.

tumour-like mass was formed below the angle of the mandible, on a level with the thyroid cartilage. On dissecting carefully it was found (1) that the spine was not affected-i.e., not eroded, \&c.-and (2) that the bleeding had extended behind the pharynx and cesophagus, forming a small tumour-like mass on the left on a level with the cricoid cartilage. 3. On opening the common carotid and tracing it up there was no aneurysmal dilatation whatever, but on a level with the cricoid cartilage there was an eroded opening through which blood had passed into the parts 